\title{
Construction and analysis of the protein-protein interaction networks for schizophrenia, bipolar disorder, and major depression
}

Sheng-An Lee ${ }^{1 \dagger}$, Theresa Tsun-Hui Tsao ${ }^{2,3 \dagger}{ }^{\dagger}$, Ko-Chun Yang ${ }^{3}$, Han Lin ${ }^{4}$, Yu-Lun Kuo ${ }^{2}$, Chien-Hsiang Hsu ${ }^{3}$, Wen-Kuei Lee ${ }^{5}$, Kuo-Chuan Huang ${ }^{2,5^{*}}$, Cheng-Yan Kao ${ }^{2,3^{*}}$

From Asia Pacific Bioinformatics Network (APBioNet) Tenth International Conference on Bioinformatics - First ISCB Asia Joint Conference 2011 (InCoB2011/ISCB-Asia 2011)

Kuala Lumpur, Malaysia. 30 November - 2 December 2011

\begin{abstract}
Background: Schizophrenia, bipolar disorder, and major depression are devastating mental diseases, each with distinctive yet overlapping epidemiologic characteristics. Microarray and proteomics data have revealed genes which expressed abnormally in patients. Several single nucleotide polymorphisms (SNPs) and mutations are associated with one or more of the three diseases. Nevertheless, there are few studies on the interactions among the disease-associated genes and proteins.

Results: This study, for the first time, incorporated microarray and protein-protein interaction (PPI) databases to construct the PPI network of abnormally expressed genes in postmortem brain samples of schizophrenia, bipolar disorder, and major depression patients. The samples were collected from Brodmann area (BA) 10 of the prefrontal cortex. Abnormally expressed disease genes were selected by t-tests comparing the disease and control samples. These genes were involved in housekeeping functions (e.g. translation, transcription, energy conversion, and metabolism), in brain specific functions (e.g. signal transduction, neuron cell differentiation, and cytoskeleton), or in stress responses (e.g. heat shocks and biotic stress).

The diseases were interconnected through several "switchboard"-like nodes in the PPI network or shared abnormally expressed genes. A "core" functional module which consisted of a tightly knitted sub-network of clique-5 and -4s was also observed. These cliques were formed by 12 genes highly expressed in both disease and control samples.

Conclusions: Several previously unidentified disease marker genes and drug targets, such as SBNO2 (schizophrenia), SEC24C (bipolar disorder), and SRRT (major depression), were identified based on statistical and topological analyses of the PPI network. The shared or interconnecting marker genes may explain the shared symptoms of the studied diseases. Furthermore, the "switchboard" genes, such as APP, UBC, and YWHAZ, are proposed as potential targets for developing new treatments due to their functional and topological significance.
\end{abstract}

\footnotetext{
* Correspondence: d94922009@ntu.edu.tw; cykao@csie.ntu.edu.tw

+ Contributed equally

${ }^{2}$ Department of Computer Science and Information Engineering, National

Taiwan University, Taipei, Taiwan

Full list of author information is available at the end of the article
} 


\section{Background}

Schizophrenia, bipolar disorder, and major depression are suffered by approximately $1 \%, 5 \%$ or $20 \%$, respectively, of human during their life time. Improving the diagnoses and treatments of these devastating diseases is an important task. However, few studies of mental diseases have used post-mortem brain samples [1]. Researchers did not have convenient access to brain samples of psychiatric patients until 1994 when the Stanley Brain Collection started.

These three diseases each have distinct characteristics, but they also share a few symptoms. All diseases above may show signs of psychosis, and in which both bipolar disorder and major depression have depressive symptoms. The shared symptoms suggest related disease mechanisms. These diseases have always been affiliated with neuron and dopamine abnormalities [2-9]. Abnormalities in the glia, GABA, and other neurotransmitter systems were revealed in more recent studies using patients' brain samples from the Stanley Brain Collections [10-15]. The genetics of these diseases are overlapped [16,17]. Related single nucleotide polymorphisms (SNPs) and mutations, such as coding variants in the lipid transporter $\mathrm{ABCA13}$, are often associated with more than one of the three diseases [1,2]. Microarrays of frontal, prefrontal, cingulate, and cerebellar cortex samples show disruption of mRNA or protein expression in intracellular signalling, synaptic neurotransmission, oligodendrocyte, stress responses, cytoskeleton, ATP biosynthesis, and translation [18-35].

The data of human protein-protein interactions (PPIs) brought insights to the network biology of diseases and explained the interrelationships among disease-related genes and proteins. Recently, the schizophrenia markers, NRG1 and CACNG2, which were considered functionally un-related, were found to be connected via the ERGG and DRL protein families in PPI network [36]. Furthermore, in our pilot study, a potential schizophrenia marker, EXOC4, was identified by analyzing the PPI network constructed using four published schizophrenic marker genes [37].

This study constructed PPI networks for schizophrenia, bipolar disorder, and major depression using abnormally expressed genes in Brodmann area (BA) 10 of prefrontal cortex. The "core" functional module of BA10 was also constructed by the most highly expressed genes in disease and control samples. Potential disease marker genes and drug targets were also identified.

\section{Methods}

This study constructed PPI networks for post-mortem prefrontal cortex of schizophrenia, bipolar disorder, and major depression patients. It focuses only on direct (physical) interactions among proteins. Genetic interactions were not investigated. The PPI networks were constructed based on the hypotheses that (1) the abundance of proteins and mRNAs were positively correlated in brains; (2) proteins were more likely to interact with proteins which had similar expression patterns or were more abundant; and (3) more abundant proteins participated in more active biological processes.

The research methodology is summarized in Figure 1. Microarray data series was used to identify genes abnormally expressed in patients' BA10 of prefrontal cortex. These genes, together with the brain specific genes, were used to construct a PPI network for topological analyses. This network was compared with the PPI networks constructed by disease genes mentioned by in published literatures. The most abundant protein interactions in BA10 were revealed by the most highly expressed genes in the brain samples to outline the framework of prefrontal cortex biochemistry.

\section{Sources of microarray data}

The raw data (CEL files) of microarray data series, GSE12654, were downloaded from Gene Expression Omnibus (GEO) and normalized by mas5 [38]. GSE12654 was first published by Iwamoto et al of RIKEN, Japan [39]. GSE12654 is the microarray data of post-mortem human brain sampled from the BA10 of four groups of people, including 13 schizophrenia patients, 11 bipolar disorder patients, 11 major depression patients, and 14 healthy controls [23]. Each group of the three diseases and the control samples was termed as a "sample group" in this study.

\section{Selection of the most highly expressed genes}

The $\mathrm{z}$-scores of genes were calculated within each disease or control sample group. Each gene had four z-scoresthree for each disease sample groups and one for the control sample group. The genes with z-scores $\geq 1.96$ in $\geq$ $49 \%$ samples of a given sample group (e.g. in $\geq 7 / 13$ schizophrenia samples) were defined as the most highly expressed genes of the sample types. These genes were likely to encode the most abundant proteins in BA10 of patients or healthy people.

\section{Selection of tissue-specific "essential" genes for the healthy BA10 samples}

GSE1133 (Human U133A/GNF1H) [40] was downloaded from the Novartis Research Foundation Gene Expression Database (GNF). The gcrma-normalized expression value of a gene in the prefrontal cortex was compared with the mean expression value of the same gene in all tissues examined in GSE1133. The genes were defined as prefrontal cortex-specific genes, if their expression values in the prefrontal cortex were $>4$ fold higher than the mean values in all tissues. The genes which were both specific 
to the prefrontal cortex, as well as highly expressed ( $\mathrm{z}-$ score $\geq 1.96$ in $\geq 49 \%$ samples) in the control sample group of GSE12654, were defined as the tissue-specific "essential" genes of healthy BA10.

\section{Selection of abnormally expressed genes in disease samples}

Considering the diverse conditions of post-mortem brain samples (e.g. pH values), the profiles of subjects (e.g. age, gender, and use of medication), and the complexity of disease mechanisms, the microarrays in GSE12654 were analyzed by 2 -tailed $t$-test. Each disease sample group was paired with the control sample group in the $t$-tests. The genes which expressed abnormally in disease samples would be detected by the corresponding probes with significant changes ( $P$ values $<0.01$ ) of signal intensities in the disease sample groups as comparing to the control.

\section{Construction of PPI networks for mental diseases}

The most highly expressed genes and abnormally expressed genes were located on the human PPI network by an updated version of POINeT [37] to construct a query-query PPI (QQPPI) or level 1 PPI (L1PPI) networks. The updated version of POINeT contains the databases listed in Table 1 and has not been published. QQPPI networks only used the query marker genes as the nodes and revealed direct interactions among these queries. L1PPIs also showed the other non-query nodes directly connecting to the queries. L1PPI network allowed analysis of an extended network and could reveal indirect interactions (via common level 1 interactors as mediators) among query genes.

\section{Topology analysis of PPI networks}

To analyse the QQPPI and L1PPI networks, cliques and centralities were calculated. A clique is a set of genes (nodes) in which every two genes (nodes) are connected by a protein interaction (edge). Cliques have been used successfully to identify protein functional units in PPI networks [41]. Nodes within cliques are more likely to form complexes [42]. In this study, cliques with 4 nodes (clique-4) or above were identified from PPI networks. They were searched against CORUM [43] and HPRD [44] for potential protein complexes.

Centrality analyses can assist in identifying significant proteins (nodes) which have relatively more PPIs (edges) in a network. The centrality of nodes in the L1PPI network which consisted of the abnormally expressed and "essential" genes was calculated by CentiBiN $[45,46]$. The centrality scores were ranked. The ranks from different centrality algorithms were fused by summing the ranking numbers [47].

\section{Gene annotation}

The highly expressed genes were classified into groups according to the Gene Ontology (GO) terms [48], using

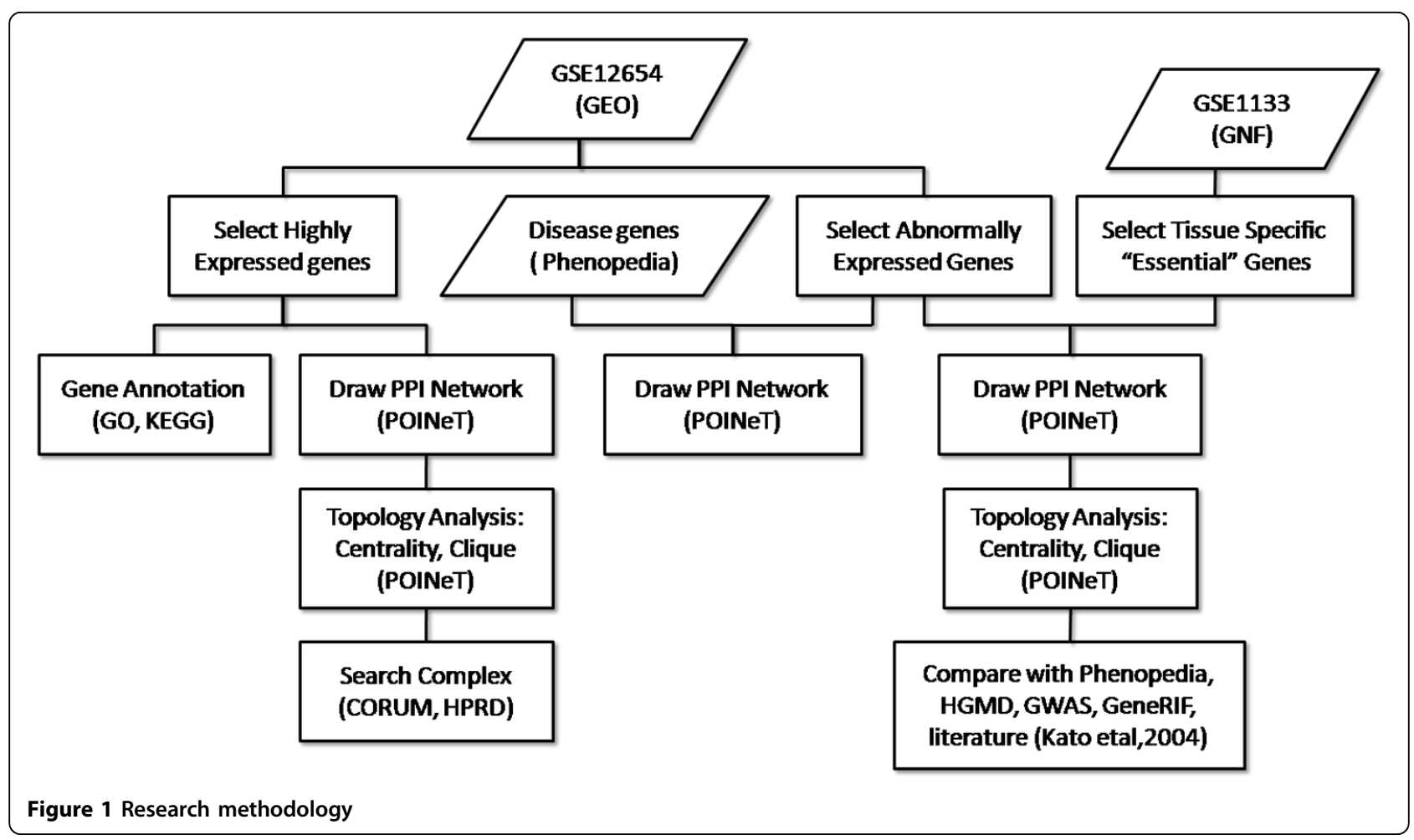


Table 1 PPI databases used for constructing PPI networks in this study

\begin{tabular}{lcc}
\hline Database & Version or downloading date & Number of recorded PPIs \\
\hline HPRD & Release 9 & 39194 \\
BioGRID & 3.1 .70 & 356818 \\
IntACT & $2010-12-06$ & 146227 \\
NCBI gene interactions & $2010-12-06$ & 585982 \\
\hline
\end{tabular}

the Functional Classification tool in DAVID 6.7 [49]. Suitable parameters for classification stringency were chosen for the Gene Functional Classification tool as followed - a Kappa similarity term overlap of 3, a Kappa similar threshold of 0.3, an initial group membership of 3, a final group membership of 3 , and a multiple linkage threshold of 0.5 .

The functions of abnormally expressed disease genes ( $\mathrm{P}$ value $<0.01$ ) were summarized using the FatiGO+ module of Babelomics 4.2 [50,51]. Functional enrichments were performed for terms in REACTOME, GO cellular localisation, GO biological process, or GO molecular function with default parameters. The functions of genes were annotated by the Gene List Report in DAVID 6.7 [49].

\section{Comparison with the study of Iwamoto [39]}

Different analytical methods of microarray data often reveal similar but not identical results. The original contributors of microarray GSE12654 were Iwamoto et al who focused on gender- and age-related genes in their analysis. The disease genes identified from GSE12654 by Iwamoto et al [39] were constructed into QQPPI and L1PPI networks and compared with ours.

\section{Comparison with data from Phenopedia, GWAS, HGMD, and GeneRIF}

Microarray studies identify changes in gene expression patterns, whereas gene association studies focus on the identification of disease-related SNPs and mutations. The disease markers revealed by these different approaches were compared with our study.

Phenopedia collect genes which associate with human diseases by retrieving curated records from PubMed on a weekly basis since 2001 [52]. The genes which were listed in Phenopedia as being associated with schizophrenia, bipolar disorder, and major depression were constructed into QQPPI and L1PPI networks, and compared with the network constructed by the abnormally expressed disease genes. The disease-associated SNPs and mutations which were listed in A Catalog of Published Genome-Wide Association Studies (GWAS) [53] or The Human Genome Mutation Database (HGMD) [54] were also compared with our findings.

In addition, dopamine, GABA, and glutamate are three of the most significant chemicals known to affect the symptoms of the studied mental diseases. The association of abnormally expressed and tissue-specific "essential" genes with dopamine, GABA, and glutamate were searched in GeneRIF.

\section{Results}

BA10 of the prefrontal cortex is believed to be responsible for cognition, which is a function disrupted often in patients of psychiatric diseases [55,56]. By analyzing the microarrays of human BA10 samples, this study identified potential disease marker genes and drug targets of schizophrenia, bipolar disorder, and major depression. Additionally, a "core" functional module was constructed using the genes which were not only highly expressed in both disease and control samples, but also topologically significant in the PPI networks.

\section{Abnormal gene expression in the prefrontal cortex of schizophrenia, bipolar disorder, and major depression patients}

The differential expression of genes in the BA10 samples was investigated by $t$-tests comparing the signal intensities of corresponding probes in microarrays for the disease and control samples. The genes of which the corresponding probes had $\mathrm{P}$ values $<0.01$ were defined as abnormally expressed and proposed as disease markers. These disease markers, together with the tissue-specific "essential" genes, were used as queries to reveal the QQPPI network shown in Figure 2. The functions of query genes are listed in Additional file 1 (titled 'Abnormally expressed disease genes and functions'). The genes and $P$ values of corresponding probes are listed in Additional file 2, 3, and 4 (titled 'Abnormally expressed genes and corresponding probe IDs and P values in $t$-tests' for 'schizophrenia', 'bipolar disorder', and 'major depression', respectively).

The abnormally expressed genes could be classified into 13 groups according to their functional annotations as detailed in Additional file 5 (titled 'GO functional classification for abnormally expressed genes'). They participated in transcription, translation, cytoskeleton, neuron differentiation, ATP-binding, cellular transportation, and many other biological processes. Using the functional enrichment tool FATIGO+, a few functional terms were found to be more abundant in our abnormally expressed proteins of BA10 than in the entire proteome encoded by human genome. Table 2 lists the GO biological processes which were enriched in our abnormally expressed genes. The results of functional enrichment analyses for GO cellular 


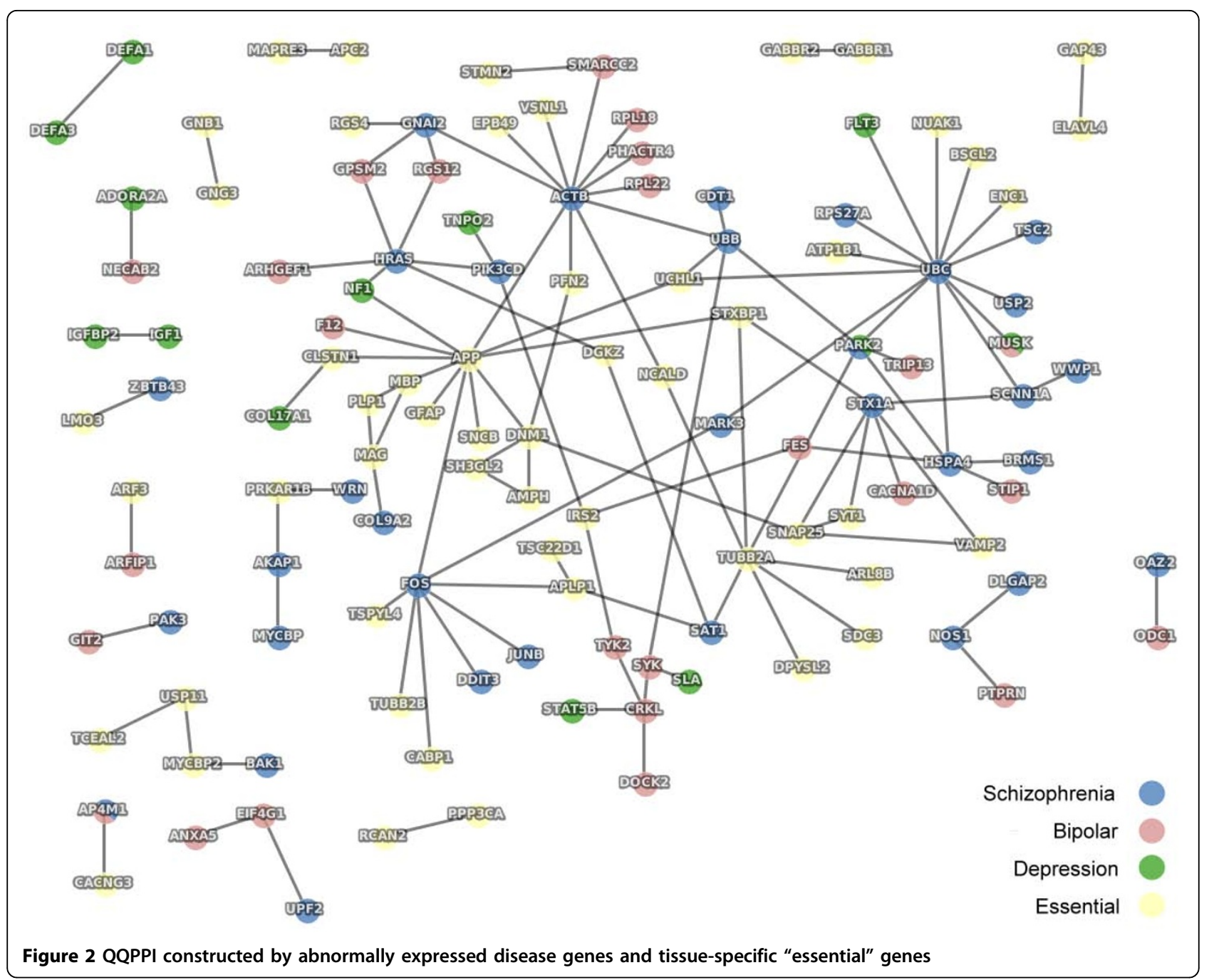

Table 2 Functional enrichment analysis for abnormally expressed disease markers

\begin{tabular}{|c|c|c|}
\hline GO: biological process & $\begin{array}{l}\text { Go term } \\
\text { ID }\end{array}$ & Genes with this term \\
\hline Translation & GO:0006412 & $\begin{array}{l}\text { DHX29, EIF4G1, FAU, GSPT1, KRT7, MAZ, RPL10A, RPL17, RPL 18, RPL21, RPL21P119, RPL21P16, RPL21P39, } \\
\text { RPL21P80, RPL21P93, RPL21P97, RPL22, RPS15A, RPS5, VARS, MRPS12, PABPC4, RPS27A, TOP3A }\end{array}$ \\
\hline $\begin{array}{l}\text { Transmission of nerve } \\
\text { impulse }\end{array}$ & GO:0019226 & $\begin{array}{l}\text { CPNE6, GABARAP, MUSK, POU3F2, VGF, ADORA2A, GRM8, NF1, NMU, PARK2, DLGAP2, GNAI2, HRAS, } \\
\text { NOS1, RPS27A, STX1A, UBB, UBC }\end{array}$ \\
\hline Synaptic transmission & GO:0007268 & $\begin{array}{l}\text { CPNE6, GABARAP, MUSK, VGF, ADORA2A, GRM8, NMU, PARK2, DLGAP2, GNAI2, HRAS, NOS1, RPS27A, } \\
\text { STX1A, UBB, UBC }\end{array}$ \\
\hline $\begin{array}{l}\text { Negative regulation of } \\
\text { catalytic activity }\end{array}$ & GO:0043086 & GNAT1, TNNI3, ADORA2A, GRM8, NF1, GNAI2, OXA1L, RPS27A, SH3BP5, TSC2, UBB, UBC \\
\hline $\begin{array}{l}\text { Regulation of synaptic } \\
\text { transmission }\end{array}$ & GO:0050804 & VGF, ADORA2A, GRM8, NMU, PARK2, GNAI2, HRAS, RPS27A, STX1A, UBB, UBC \\
\hline Translational elongation & GO:0006414 & $\begin{array}{l}\text { FAU, RPL10A, RPL17, RPL18, RPL21, RPL21P119, RPL21P16, RPL21P39, RPL21P80, RPL21P93, RPL21P97, } \\
\text { RPL22, RPS15A, RPS5, VARS, RPS27A }\end{array}$ \\
\hline $\begin{array}{l}\text { Regulation of } \\
\text { synaptogenesis }\end{array}$ & GO:0051963 & MUSK, RPS27A, UBB, UBC \\
\hline $\begin{array}{l}\text { Polyamine metabolic } \\
\text { process }\end{array}$ & GO:0006595 & ODC1, SLC6A11, OAZ2, SAT1 \\
\hline
\end{tabular}


compartment, GO molecular function, and REACTOME are detailed in Additional file 6 (titled 'FatiGO term enrichment with $P$ values smaller than 0.01). Enriched functions can be classified into five groups-(1) neuron and signal transduction-related, such as neuron projection, transmission of nerve impulse, synaptic transmission, synaptogenesis, and signalling by NGF; (2) cytoskeleton; (3) gene expression, such as translation and ribosomes; (4) metabolisms of lipids, lipoproteins, proteins, polyamines, and sugars (diabetes); and (5) stresses, such as influenza infection. The enrichment of neuron and signal transduction-related functions was expected. Abnormality in translation-related genes has been observed in previous studies $[39,57]$. Abnormality in cytoskeleton genes could lead to disrupted cellular mobility of Golgi apparatus, which has a place in neuron signal transduction [58-61]. Previous studies have also shown abnormal expression of ATP-related or mitochondrial genes [20,22,62-64]. The enriched metabolism functions can be further evidences of abnormal energy conversion in patients' prefrontal cortex. The relationship to influenza infection can be explained as biotic stress; and stresses have often been reported as inducers of mental diseases [65-67].

The ranks of centrality were calculated by various algorithms and are listed in Additional file 7 (titled 'Centrality analysis of abnormally expressed genes in QQPPI network'). The top ranked nodes are summarised in Table 3. Proteins which rank higher in centrality analyses of PPI networks usually have more crucial biological functions [68]. The top ranked nodes (e.g. UBC, UBB, and ACTB) were therefore proposed as having critical roles in disease mechanisms. Only three clique-3s were found (data not shown). Clique-4 or above was not identified as a result of the looser network formed by the abnormally expressed genes (Figure 2) in comparison with the tightly knitted network formed by the highly expressed genes (Figure 3 ).

\section{The disease marker genes identified through different analytical approaches were connected in PPI networks} The microarray data series used in this study has been analysed by the original contributors, Iwamoto et al [39]. In the studied mental diseases, Iwamoto et al revealed down-regulation of receptor-, transporter-, and channelencoding genes; and up-regulation of transcription-, translation-, stress- and molecular chaperon-related genes [39]. Although the genes identified in our studies were not identical to the findings of Iwamoto et al, they fall into similar functional categories. Although few of our disease markers had direct protein interactions with the ones described in Iwamoto et al [39], many had

Table 3 Centrality analysis of PPI network

\begin{tabular}{|c|c|c|c|}
\hline $\begin{array}{c}\text { Gene } \\
\text { symbol }\end{array}$ & $\begin{array}{l}\text { Disease(s) or essential } \\
\text { gene* }\end{array}$ & Gene function(s) & $\begin{array}{l}\text { Sum of } \\
\text { ranks** }\end{array}$ \\
\hline UBC & $\mathrm{S}$ & - ubiquitin $\mathrm{C}$ & 7 \\
\hline ACTB & $\mathrm{S}$ & - actin, beta & 15 \\
\hline UBB & $\mathrm{S}$ & - ubiquitin B & 29 \\
\hline APP & $\mathrm{E}$ & - amyloid beta (A4) precursor protein & 32 \\
\hline FOS & $\mathrm{S}$ & - $v$-fos FBJ murine osteosarcoma viral oncogene homolog & 51 \\
\hline HSPA4 & $\mathrm{S}$ & - heat shock 70kDa protein 4 & 54 \\
\hline PARK2 & SD & - Parkinson disease (autosomal recessive, juvenile) 2, parkin & 67 \\
\hline SYK & B & - spleen tyrosine kinase & 97 \\
\hline TUBB2A & $\mathrm{E}$ & - tubulin, beta $2 \mathrm{~A}$ & 117 \\
\hline TSC2 & $\mathrm{S}$ & - tuberous sclerosis 2 & 127 \\
\hline UCHL1 & $\mathrm{E}$ & - ubiquitin carboxyl-terminal esterase L1 (ubiquitin thiolesterase) & 217 \\
\hline MARK3 & $\mathrm{S}$ & - MAP/microtubule affinity-regulating kinase 3 & 236 \\
\hline RPS27A & $\mathrm{S}$ & - ribosomal protein S27a pseudogene 12; ribosomal & 355 \\
\hline DNM1 & $\mathrm{E}$ & - dynamin 1 & 476 \\
\hline IRS2 & $\mathrm{E}$ & - insulin receptor substrate 2 & 497 \\
\hline GNAI2 & $\mathrm{S}$ & - guanine nucleotide binding protein ( $G$ protein), alpha inhibiting activity polypeptide 2 & 519 \\
\hline SMARCC2 & B & $\begin{array}{l}\text { - SWI/SNF related, matrix associated, actin dependent regulator of chromatin, subfamily } \\
\qquad \text { C, member } 2\end{array}$ & 525 \\
\hline HRAS & $\mathrm{S}$ & - v-Ha-ras Harvey rat sarcoma viral oncogene homolog & 527 \\
\hline SAT1 & $\mathrm{S}$ & - spermidine/spermine N1-acetyltransferase 1 & 529 \\
\hline CRKL & B & - v-crk sarcoma virus CT10 oncogene homolog (avian)-like & 531 \\
\hline
\end{tabular}

The L1PPI network (not shown) was constructed by abnormally expressed disease markers, tissue-specific "essential" genes

*The listed genes were found abnormally expressed in samples of schizophrenia (S), bipolar disorder (B) or major depression (D), or were tissue-specific "essential" (E) genes.

**The sum of centrality ranks calculated using various centrality algorithms for the disease and "essential" genes shown in Figure 2 . 


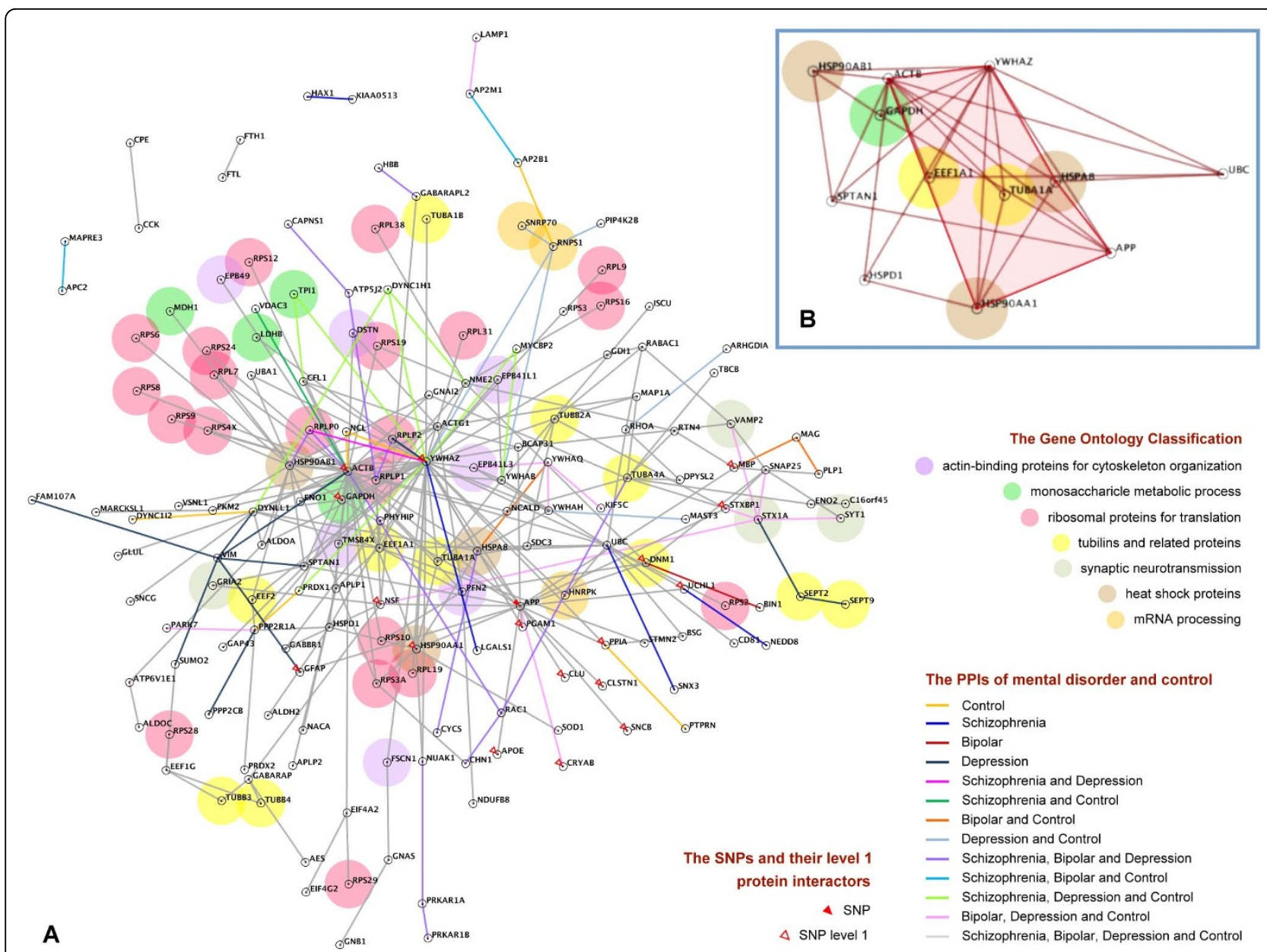

Figure 3 a) QQPPI constructed by highly expressed genes in disease and control samples; b) The "core" functional module

indirect interactions through mediator proteins (level 1 interactors) in between. Taking bipolar disorder as an example, there was only one gene listed in both Iwamoto et $a l$ and this study as a disease marker; only two of our abnormally expressed genes for bipolar dirorder had direct interactions (PPIs) with two bipolar disorder markers of Iwamoto et al. However, our markers of bipolar disorder shared 120 level 1 interactors with the bipolar disorder markers of Iwamoto et al [39].

Similar results were observed in the data of Phenopedia as summarized in Table 4. For schizophrenia, bipolar disorder, and major depression, there were only 11,5 , and 5 genes, respectively, that were listed both as disease genes in Phenopedia and as our disease markers. Interestingly, there were many PPIs formed between the Phenopedia disease genes and our abnormally expressed genes for schizophrenia, bipolar disorder, and major depression as illustrated in Additional file 8, 9, and 10 (titled 'Interrelationship between Phenopedia and abnormally expressed genes' in 'schizophrenia', 'bipolar disorder', and 'major depression', respectively). The names of these disease genes are listed in Additional file 11 (titled 'Comparison of disease genes listed in Phenopedia, HGMD, and GWAS'). The diseases associated SNPs and mutations

Table 4 Comparison to the disease genes listed in Phenopedia

\begin{tabular}{cccc}
\hline Record type & Schizophrenia & Bipolar disorder & Major depression \\
\hline Disease genes in Phenopedia (P) & 1001 & 722 & 226 \\
Abnormally expressed genes (T) & 110 & 100 & 44 \\
Both P and T (shared nodes) & 11 & 5 & 1 \\
PPls between P and T & 252 & 73 & 11 \\
\hline
\end{tabular}

* Genes with $P$ values $<0.01$ in $t$-tests 
which are listed in GWAS and HGMD were also compared with the abnormally expressed genes identified in this study and listed also in Additional file 8.

Furthermore, dopamine, GABA, and glutamate are critical chemicals affecting the symptoms of schizophrenia, bipolar disorder, and major depression. Genes which were described in GeneRIF as involving in the biochemistry of these chemicals are listed in Table 5. This data was considered as the indirect evidence to the association of genes to the studied mental diseases.

\section{The highly expressed genes and the most abundant protein interactions in the prefrontal cortex}

In order to identify the most abundant protein interactions in BA10, the PPI network of highly expressed genes were constructed for schizophrenia, bipolar disorder, major depression, and healthy control samples as illustrated in Figure 3a. Many PPIs were shared by two or more of the diseases. Disease-associated SNPs, mutations, and GO functional classes were identified for each gene and labelled as shown in Figure 3a.

In this PPI network, there were one clique-5 and several clique-4s that tightly knitted into a sub-network containing 12 genes as shown in Figure 3b. These 12 genes in the BA10 cliques encode four heat shock proteins (HSPA8, HSP90AA1, HSPD1, HSP90AB1), the tubulin protein (TUBA1A), the ubiquitin protein (UBC), the actin-binding cytoskeleton protein (SPTAN1), beta-actin

Table 5 Genes which participated in the biochemistry of GABA, glutamate, or dopamine

\begin{tabular}{|c|c|c|c|}
\hline Gene Symbol & GABA & Glutamate & Dopamine \\
\hline APP & + & + & + \\
\hline GABBR2 & + & + & \\
\hline GABBR1 & + & + & \\
\hline SLC12A5 & + & & \\
\hline GABARAP & + & & \\
\hline SLC1A3 & & + & \\
\hline NOS1 & & + & \\
\hline GRM8 & & + & \\
\hline GLUL & & + & \\
\hline UCHL1 & & & + \\
\hline SYNGR3 & & & + \\
\hline STXBP1 & & & + \\
\hline STX1A & & & + \\
\hline SNCB & & & + \\
\hline PRKAR1B & & & + \\
\hline PARK2 & & & + \\
\hline IGF1 & & & + \\
\hline GPR143 & & & + \\
\hline EPB41L1 & & & + \\
\hline CRYAA & & & + \\
\hline ADORA2A & & & + \\
\hline
\end{tabular}

(ACTB), the energy generating glyceraldehyde-3-phosphate dehydrogenase (GAPDH), translation elongation factor (EEF1A1), signal transduction protein (YWHAZ), and amyloid beta (A4) precursor protein (APP). This sub-network of 12 highly expressed and topologically significant genes was proposed as the "core" functional module of BA10 for both patients and healthy people.

\section{Discussion}

This study combined data of quantitative transcriptomics and PPIs for statistical and topological analyses. New disease marker genes and potential drug targets were revealed. Shared disease mechanisms, although hypothetical at the present, were proposed based on common marker genes and interconnecting PPIs to explain the shared symptoms among diseases. A "core" functional module of BA10 was also proposed.

\section{Disease markers and potential drug targets}

The genes which had P values $<0.01$ in our $t$-tests were defined as abnormally expressed in disease samples. These genes were proposed as disease marker genes and constructed into a PPI network as illustrated in Figure 2.

Previous studies have shown that the probes (and the genes which they represented) with lower $P$ values appeared as more effective clustering features for separating the disease samples from the controls in hierarchical clusters (unpublished data). The observation suggested that genes with lower $\mathrm{P}$ values are more important disease markers.

The genes with the lowest $\mathrm{P}$ values in our $t$-tests were not well-studied genes. SBNO2 was a gene of which the probe had the lowest $\mathrm{P}$ value in the $t$-test comparing schizophrenia and control samples. SBNO2 has a strawberry notch homolog in fruit fly. The gene is involved in the anti-inflammatory signalling pathway [69]. It has also been associated with type 2 diabetes mellitus, of which shared many disease genes with mental diseases [52,70]. SEC24C was a gene of which the probe had the lowest $P$ value in the $t$-test comparing bipolar disorder and control samples. SEC24C encodes a protein which may be involved in ER to Golgi vesicular transportation [71]. It has been associated another mental disease, Alzheimer's disease [52]. SRRT was a gene of which the probe had the lowest $\mathrm{P}$ value in the $t$-test comparing major depression and control samples. SRRT is possibly involved in transcriptional regulation and RNA metabolism as it is a homolog to an Arabidopsis serrate RNA effector [72]. Apart from this study, SBNO2, SEC24C and SRRT have never been associated with schizophrenia, bipolar disorder, or major depression; these genes did not form PPI with any of our abnormally expressed marker genes, either.

There appeared a weak negative correlation between the $P$ values of a gene (probe) and its centrality ranks in 
this study. More "essential" proteins in PPI networks have also been shown to rank higher than less important proteins in centrality analyses [68,73]. Interestingly, the nodes which ranked highest in the centrality studies were mostly schizophrenia markers as listed in Table 3. The top ranked genes in centrality analysis, UBC, $A C T B$, and UBB, were all abnormally expressed in schizophrenia samples. UBC and UBB encode the polyubiquitin precursors. ACTB encodes the beta-actin protein. The roles of these proteins in mental disease mechanisms are not clear. None of these three genes have been associated with any mental disease; but UBC has been associated also with type 2 diabetes mellitus [70].

Schizophrenia samples had the largest number of abnormally expressed genes, and major depression had the fewest. The above observations aligned with the most severe and complex symptoms of schizophrenia in comparison to the other two diseases; major depression encompassed the least of symptoms. All three disorders may show signs of psychosis, but symptoms such as hallucinations and poverty of speech are usually only seen with schizophrenia. The delusions associated with bipolar disorder and major depression is usually the milder "mood-congruent" delusion contributing to the overly positive or negative self perceptions of manic or depressive patients. Whereas the delusions occur with schizophrenia can be completely implausible and "bizarre". The additional symptoms of schizophrenia may be caused by additional aberrations of genes. It must be noted, however, that few evidences are available to support or clarify this assumption.

\section{Shared disease mechanisms}

The three studied mental diseases are genetically related and share disease genes [16,17]. Each disease may have malfunctions in multiple biological pathways, and the same malfunctions may occur in multiple diseases [74]. There are also increasing numbers of evidences which indicate correlations in genetic risks for schizophrenia and bipolar disorder [75-79].

A few genes were found to be abnormally expressed in more than one disease in this study. As shown in Figure 2, MUSK, which encodes a protein responsible for the assembly of receptors in post-synaptic neuromuscular junctions, was abnormally expressed in samples of bipolar disorder and major depression [80,81]. PARK2, a gene of unknown function associated with related phenotypes such as Parkinson disease, nerve degeneration, cognition disorders, visual perception, attention, and memory, was abnormally expressed in schizophrenia and major depression [52,82-84]. AP4M1, which encodes a subunit of AP-4 complex responsible for transportation of proteins from Golgi, was abnormally expressed in schizophrenia and bipolar disorder $[52,85]$. Many of the genes were also found to be highly expressed in more than one disease as shown in Figure 3a.

One might hypothesize that the shared genes are the reasons for shared symptoms - the abnormal expression of MUSK may cause the depression of bipolar disorder and major depression; PARK2 may cause the psychosis symptoms such as delusions, avolition, blunted effect, asociality, and cognitive dysfunction, which are commonly seen with varying severities in both schizophrenia and major depression; AP4M1 may cause the psychosis symptoms such as the less "bizarre" forms of delusions and restlessness sometimes observed in both schizophrenia and bipolar disorder. These hypotheses are far from being conclusive. Further researches such as mutant studies in animal models, genetic association studies, and gene and protein expression analyses are required to better explain the observed phenomenon of overlapping PPI network of the mental diseases. Unfortunately, as symptoms such as hallucinations and delusions are uniquely human, the exact roles of disease-associated genes play in mental disease mechanisms are difficult to be studied using mutant model animals [86].

The centrality ranks of MUSK, PARK2, and AP4M1 might indicate the divergence or similarity of the studied mental diseases, if phenotypical similarities were positively correlated with similarities in disease mechanisms. In the PPI network constructed using 3550 human disease genes retrieved from OMIM Morbid Map, shared genes were more central than disease-specific genes, and the genes shared by phenotypically similar diseases are less central than the ones shared by phenotypically divergent diseases [73]. AP4M1 ranked the lowest in centrality among the three genes as shown in Fig. 2; PARK2 ranked the highest. We might deduce that the disease mechanisms of schizophrenia and bipolar disorder are most similar among the three studied diseases; and the disease mechanisms of schizophrenia and major depression are most diverged.

\section{"Switchboards" in PPI sub-networks of psychiatric diseases}

Apart from shared marker genes, marker genes of multiple diseases sometimes interact with the same critical nodes. These critical nodes were designated as "switchboard" nodes to describe their place in interconnecting PPIs of different diseases. The "switchboards" usually ranked higher in centrality analyses, suggesting they are more "essential" and effect diverged ranges of phenotypes. The abnormalities of different protein interactions with the same gene may explain the relevant but different symptoms of the studied diseases.

In the schizophrenia PPI network shown in figure 2, the "switchboard" APP interacted with the abnormally 
expressed ACTB and FOS. APP was a tissue-specific "essential" gene, which encodes a highly expressed betaamyloid precursor protein. ACTB encodes the betaactin, which is responsible for cellular structure and (neuron signal) mobility [87-89]. FOS is likely to associate with cell differentiation, apoptotic cell death, and depression-related diseases such as bulimia and anorexia $[52,90]$. In bipolar disorder, APP interacted with the abnormally expressed F12. F12 encodes a coagulation factor which circulates in blood as zymogen. Mutations in F12 may prolong whole-blood clotting time; and the gene has been associated with type 1 and 2 diabetes mellitus [52,91-93]. In major depression, APP interacted with the abnormally expressed NF1. NF1 encodes a neurofibromin responsible for signal transduction, and has been associated with mental retardation and autism $[52,94,95]$. APP has been listed in the HGMD as being associated with schizophrenia [96]. However, the transcript of APP was consistently highly abundant in all disease and control samples. The mutation of APP in patients might not have affected its transcription.

A "switchboard" can also be a disease gene. For example, the ubiquitous protein, UBC, was abnormally expressed in schizophrenia samples and interacted with the maker genes of schizophrenia (i.e. TSC2, SCNN1A and USP2), bipolar disorder (i.e. MUSK), and major depression (i.e. MUSK and FLT3).

The same "switchboard" mechanism was observed in the network constructed by the most highly expressed genes. One such example was YWHAZ, which encodes a signal transduction protein. YWHAZ interacted with 43 nodes as shown in Figure 3a and was highly expressed in disease and control samples. The abnormal PPIs (i.e. PPIs of highly expressed genes that did not occur in the controls) between YWHAZ and many other proteins were observed in disease samples. The interaction with NCL was abnormal in schizophrenia, bipolar disorder, and major depression. The other YWHAZ abnormalities were the interactions with RNPS1 and LGALS1 in schizophrenia; the interactions with MYCBP2, PRDX1 or TP1l in bipolar disorder; the interactions with RPLP2 and VIM in major depression; and the interactions with RPLPO in both schizophrenia and major depression.

\section{The "core" functional module}

We proposed that the 12 genes in the clique- 5 and $-4 \mathrm{~s}$ in PPI constructed by the highly expressed genes were central to the functioning of BA10 (Figure $3 a$ and $b$ ). These nodes were the ones with the highest ranks in the centrality analysis of PPI network of highly expressed gene. A few genes, such as UBC and ACTB, were also highly ranked in the centrality analysis of the abnormally expressed PPI network as listed in Table 3. Many of these genes encode members of important protein complexes as summarised in Table 6 . They were mostly tissue-specific "essential" genes and highly expressed in all three studied mental diseases as well as healthy control. The nodes in cliques were sometimes involved in biological processes which were disrupted in schizophrenia, bipolar disorder, or major depression.

\section{Teams of disease marker genes}

The abnormally expressed genes identified in this study were compared with published disease associated genes from previous analysis of the same data series (GSE12654), Phenopedia, GWAS, and HGMD. Although few genes were consistently identified in diseases by different groups of researchers, many of these genes were found to form QQPPIs or share the same level 1 PPI interactors as shown in Table 4 and Additional file 8, 9, and 10.

Table 6 Cliques in the PPI network constructed by highly expressed genes in disease and control samples

\begin{tabular}{|c|c|c|c|c|}
\hline \multicolumn{4}{|c|}{ List of clique-4 } & \multirow{2}{*}{$\begin{array}{l}\text { Protein complex } \\
\text { - Nil }\end{array}$} \\
\hline HSPA8 & HSP90AA1 & APP & YWHAZ & \\
\hline HSPA8 & HSP90AA1 & APP & ACTB & - Amyloid beta protein oligomer (PMID:15834427) \\
\hline HSPA8 & HSP90AA1 & ACTB & YWHAZ & - APP-FE65-LRP complex (PMID:15115822) \\
\hline HSPA8 & APP & ACTB & YWHAZ & - APP-TIMM23 complex (PMID:16943564) \\
\hline HSP90AA1 & APP & ACTB & YWHAZ & - APP-TOMM40 complex (PMID:16943564) \\
\hline HSP90AA1 & ACTB & YWHAZ & TUBA1A & - Emerin architectural complex (PMID:17620012) \\
\hline GAPDH & HSP90AB1* & ACTB & YWHAZ & - Emerin complex 25 (PMID:17620012) \\
\hline GAPDH & APP & ACTB & YWHAZ & • Emerin-actin-NMI- (PMID:alphall) spectrin complex (PMID:17620012) \\
\hline HSPA8 & ACTB & $\mathrm{UBC} C^{*}$ & YWHAZ & - Kinase maturation complex 1 (PMID:14743216) \\
\hline HSP90AB1* & ACTB & SPTAN1 & YWHAZ & - P2X7 receptor signaling complex (PMID:11707406) \\
\hline HSP90AA1 & HSPD1 & ACTB & YWHAZ & - Profilin 2 complex (PMID:9463375) \\
\hline $\mathrm{EEF} 1 \mathrm{~A} 1^{*}$ & ACTB & UBC* & YWHAZ & - Profilin 2 complex (PMID:9463375) \\
\hline APP & ACTB & SPTAN1 & YWHAZ & - Nil \\
\hline
\end{tabular}

The protein complexes which may contain nodes within these cliques-4s are listed.

* This protein was not documented as a member of the suggested protein complex. 
The observations above suggested that, in brains of patients, disease genes can become defected due to various abnormalities and lead to the same symptoms. Each research approach may only detect a sub-set of abnormalities, such as mutation, significant changes in gene expression, or smaller changes in gene expression. Besides, only a snapshot of transcript abundance can be detected in post-mortem brain samples. The proteins were likely to work in teams-the failure of any team members at any given time may similarly disrupt the participating biological process and cause similar phenotypes. A protein team may be a set of proteins which have direct physical interactions, such as QQPPIs, or via a common protein, such as in the more extended L1PPIs. A more stringent definition of a protein team can be a set of proteins which form cliques. The teams may also be defined by genetic interactions, although it may not be applicable for human samples which cannot have synthetic lethal experiments; nonetheless, redundancy or overlapping of gene functions may be speculated with sequence homology.

\section{Network medicine}

Psychiatric drugs may be developed based on the concepts of network medicine. Network analysis of disease genes have been shown to significantly accelerate the trials for new treatments [97].

Combining drugs to target the largest number of disease genes in a PPI network, while avoiding non-disease genes to avoid side effects, has been shown to create effective new treatments for complex diseases [98]. Besides, topologically significant non-markers can also be potential drug targets so that the "switchboard" gene APP and its neighbouring nodes were proposed as potential drug targets [99]. APP is a cell surface receptor and trans-membrane precursor which can be cleaved to from peptides. The exact function of APP was not clear, but its roles in cellular signalling neuronal adhesion and positioning in cortical layers have been observed in mice models $[100,101]$. APP has also been reported to participate in the biochemistry of GABA, dopamine, and glutamate (Table 5), which are all known to have significant places in the symptoms of the studied mental diseases. Abnormal accumulation of APP protein has long been associated with Alzheimer's disease [102]. The polymorphism of APP has also been associated with schizophrenia as listed in HGMD, although its gene expression was not significantly different in disease samples of this study. The gene's association with cognition, dementia, and type 2 diabetes mellitus have also been mentioned [52]. The other "switchboards", including UBC and YWHAZ, and their neighbouring nodes can also be potential targets for developing new treatments.

\section{Limitations of the research methods}

This study analysed the disease mechanisms by considering the interactions of the proteins and employing topological analyses. However, the extensiveness of PPI subnetworks was limited by the availability of PPI recorded in the PPI databases listed in Table 1. Markers whose PPI data were not recorded in databases would be excluded in the proposed PPI networks. The incomplete human PPI network could lead to incomplete PPI network for the disease samples; it could also bias the topological analyses. The significance of disease markers was therefore evaluated by both $t$-tests and centrality analyses. Besides, abnormalities such as deformed protein structures were not observable in this study. This study only proposed disease markers which can be detected by examining the transient abundances of mRNAs. The functions of many disease marker genes were speculated by homologous genes in other model organisms and required confirmation.

\section{Conclusions}

By identifying abnormally expressed genes in post-mortem brain samples of mental disease patients, several disease marker genes were proposed for schizophrenia, bipolar disorder, and major depression. The disease markers were constructed into PPI networks and analysed by topological theories.

A few genes were shared among the studied diseases, such as MUSK, PARK2, and AP4M1. They are evidences of shared disease mechanisms. The studied diseases also shared disease genes with the other mental diseases, such as Alzheimer's and Parkinson, and metabolic diseases, such as type 1 and 2 diabetes mellitus. The research methodology of this study may be applied to expand our investigations to related diseases. Genes with higher P values, ranked lower in centrality analyses and not shared among diseases are proposed as more effective disease marker genes; the abnormal expression of these genes are more likely to be unique to a specific disease.

Nevertheless, disease markers which ranked higher in centrality analyses, interacted with the "switchboards", or were members of the "core" functional module, were considered to have more "essential" roles in the disease mechanisms. These genes included SBNO2, CEACAM5, AKAP1, UBC, ACTB, UBB, and FOS for schizophrenia; SEC24C, PGLYRP1, ARHGAP4, RPL22, SLC6A11, and SYK for bipolar disorder; and SRRT, PARK2, LILRA4, STK17A, IGFBP2, and NF1 for major depression. These markers, together with the "switchboards" such as APP, $\mathrm{UBC}$, and YWHAZ, were proposed as targets for drug development.

The three studied mental diseases showed aberrations in common biological processes. Most of the disease 
markers fall into the functional categories which have been previously proposed as being related to the three studied mental diseases. Based on published data and the results of this study, it might be said that the stress responses, cellular signal transduction, neuron cell differentiation and aging, energy metabolism, and translation were dysfunctional in patients suffering schizophrenia, bipolar disorder, or major depression. However, we are still far from drawing a clear picture of the molecular biology of patients' brains. Extensive studies are still required for establishing the disease mechanisms.

\section{Additional material}

Additional file 1: Abnormally expressed disease genes and

\section{functions}

Additional file 2: Abnormally expressed genes and corresponding probe IDs and $\mathrm{P}$ values in $t$-tests for schizophrenia

Additional file 3: Abnormally expressed genes and corresponding probe IDs and $\mathrm{P}$ values in $t$-tests for bipolar disorder

Additional file 4: Abnormally expressed genes and corresponding probe IDs and $P$ values in $t$-tests for major depression

Additional file 5: GO functional classification for abnormally expressed genes

Additional file 6: FATIGO term enrichment with $P$ values smaller than 0.01

Additional file 7: Centrality analysis of abnormally expressed genes in QQPPI network

Additional file 8: Interrelationship between Phenopedia and abnormally expressed genes in schizophrenia

Additional file 9: Interrelationship between Phenopedia and abnormally expressed genes in bipolar disorder

Additional file 10: Interrelationship between Phenopedia and abnormally expressed genes in major depression

Additional file 11: Comparison of disease genes listed in Phenopedia, HGMD, and GWAS

\section{List of abbreviations used}

BA: Brodmann Area; Bi: bipolar disorder; Co: control; De: major depression; GEO: Gene Expression Omnibus; GO: Gene Ontology; GOA: Gene Ontology Annotation; GWAS: A Catalog of Published Genome-Wide Association Studies; HGMD: The Human Genome Mutation Database; L1PPI: level 1 protein-protein interaction; LDL: low-density lipoprotein; PPI: protein-protein interaction; QQPPI: query-query protein-protein interaction; Sc: schizophrenia; single SNP: nucleotide polymorphism.

\section{Acknowledgements}

We wish to thank National Science Council, Taiwan, for funding this study and National Taiwan University for providing space and facilities. We were grateful that Computer and Information Networking Center, National Taiwan University provided high-performance computing facilities. This research project was funded by NSC grant (Project ID: NSC98-2221-E-002-141-MY2). TTHT was also funded by the NSC grants (Project ID: 098-2811-E-002-106 and 099-2811-E-002-021). This study was also supported by Armed Forces Beitou Hospital. We also thanked RIKEN for generously making their precious microarray data series, GSE12654, available on-line. This paper was kindly edited and proofread by Yan Ge.

This article has been published as part of BMC Bioinformatics Volume 12 Supplement 13, 2011: Tenth International Conference on Bioinformatics First ISCB Asia Joint Conference 2011 (InCoB/ISCB-Asia 2011): Bioinformatics.
The full contents of the supplement are available online at http://www. biomedcentral.com/1471-2105/12?issue=S13.

\section{Author details}

'Department of Information Management, Kainan University, Taoyuan, Taiwan. '2Department of Computer Science and Information Engineering, National Taiwan University, Taipei, Taiwan. ${ }^{3}$ Graduate Institute of Biomedical Electronics and Bioinformatics, National Taiwan University, Taipei, Taiwan. ${ }^{4}$ Graduate Institute of Electronics Engineering, National Taiwan University, Taipei, Taiwan. ${ }^{5}$ Department of Psychiatry, Armed Forces Beitou Hospital, Taipei, Taiwan

\section{Authors' contributions}

SAL conceived the study, programmed the bioinformatics analysis tools, carried out the data analysis and assisted in drafting the manuscript. TTHT conceived the study, interpreted the results, drafted the manuscript, surveyed the microarray data, and contributed to the design of the bioinformatics analysis tools. KCY assisted in the interpretation of results, drafting of the manuscripts, and contributed to the design of the bioinformatics analysis tools. LH programmed the bioinformatics analysis tools and carried out the data analysis. YLK and $\mathrm{CHH}$ assisted in data analyses. WKL assisted in the interpretation of results. $\mathrm{KCH}$ contributed to drafting the manuscript, interpretation of the data, and project management. CYK conceived the study and participate in coordination and management of the research project.

\section{Conflicts of interests}

The authors confirm that they have no conflict of interest.

Published: 30 November 2011

\section{References}

1. Harrison PJ: Using our brains: the findings, flaws, and future of postmortem studies of psychiatric disorders. Biol Psychiatry 2011, 69:102-103.

2. Egan MF, el-Mallakh RS, Suddath RL, Lohr JB, Bracha HS, Wyatt RJ: Cerebrospinal fluid and serum levels of neuron-specific enolase in patients with schizophrenia. Psychiatry Res 1992, 43:187-195.

3. Heckers S, Heinsen H, Geiger B, Beckmann H: Hippocampal neuron number in schizophrenia. A stereological study. Arch Gen Psychiatry 1991, 48:1002-1008.

4. Goode DJ, Manning AA: Specific imbalance of right and left sided motor neuron excitability in schizophrenia. J Neurol Neurosurg Psychiatry 1988, 51:626-629.

5. Young KA, Holcomb LA, Yazdani U, Hicks PB, German DC: Elevated neuron number in the limbic thalamus in major depression. Am J Psychiatry 2004, 161:1270-1277.

6. Manaye KF, Lei DL, Tizabi Y, Davila-Garcia MI, Mouton PR, Kelly PH: Selective neuron loss in the paraventricular nucleus of hypothalamus in patients suffering from major depression and bipolar disorder. $J$ Neuropathol Exp Neurol 2005, 64:224-229.

7. Schmidt K, Nolte-Zenker B, Patzer J, Bauer M, Schmidt LG, Heinz A: Psychopathological correlates of reduced dopamine receptor sensitivity in depression, schizophrenia, and opiate and alcohol dependence. Pharmacopsychiatry 2001, 34:66-72.

8. Benkert O, Grunder G, Wetzel H: Dopamine autoreceptor agonists in the treatment of schizophrenia and major depression. Pharmacopsychiatry 1992, 25:254-260.

9. Zhan L, Kerr JR, Lafuente MJ, Maclean A, Chibalina MV, Liu B, Burke B, Bevan S, Nasir J: Altered expression and coregulation of dopamine signalling genes in schizophrenia and bipolar disorder. Neuropathol Appl Neurobiol 2011, 37:206-219.

10. Cotter D, Mackay D, Chana G, Beasley C, Landau S, Everall IP: Reduced neuronal size and glial cell density in area 9 of the dorsolateral prefrontal cortex in subjects with major depressive disorder. Cereb Cortex 2002, 12:386-394.

11. Cotter DR, Pariante CM, Everall IP: Glial cell abnormalities in major psychiatric disorders: the evidence and implications. Brain Res Bull 2001, 55:585-595.

12. Cotter D, Mackay D, Landau S, Kerwin R, Everall I: Reduced glial cell density and neuronal size in the anterior cingulate cortex in major depressive disorder. Arch Gen Psychiatry 2001, 58:545-553. 
13. Ongur D, Jensen JE, Prescot AP, Stork C, Lundy M, Cohen BM, Renshaw PF: Abnormal glutamatergic neurotransmission and neuronal-glial interactions in acute mania. Biol Psychiatry 2008, 64:718-726.

14. Bowley MP, Drevets WC, Ongur D, Price JL: Low glial numbers in the amygdala in major depressive disorder. Biol Psychiatry 2002, 52:404-412.

15. Ongur D, Drevets WC, Price JL: Glial reduction in the subgenual prefrontal cortex in mood disorders. Proc Natl Acad Sci U S A 1998, 95:13290-13295.

16. Maier W, Hofgen B, Zobel A, Rietschel M: Genetic models of schizophrenia and bipolar disorder: overlapping inheritance or discrete genotypes? Eur Arch Psychiatry Clin Neurosci 2005, 255:159-166.

17. Berrettini W: Bipolar disorder and schizophrenia: not so distant relatives? World Psychiatry 2003, 2:68-72.

18. Harris LW, Lockstone HE, Khaitovich P, Weickert CS, Webster MJ, Bahn S: Gene expression in the prefrontal cortex during adolescence: implications for the onset of schizophrenia. BMC Med Genomics 2009, 2:28.

19. Harris LW, Wayland M, Lan M, Ryan M, Giger T, Lockstone H, Wuethrich I, Mimmack $M$, Wang $L$, Kotter $M$, et al: The cerebral microvasculature in schizophrenia: a laser capture microdissection study. PLoS One 2008, 3: e3964.

20. Rollins B, Martin MV, Sequeira PA, Moon EA, Morgan LZ, Watson SJ, Schatzberg A, Akil H, Myers RM, Jones EG, et al: Mitochondrial variants in schizophrenia, bipolar disorder, and major depressive disorder. PLOS One 2009, 4:e4913.

21. Mehta D, Menke A, Binder EB: Gene expression studies in major depression. Curr Psychiatry Rep 2010, 12:135-144.

22. Iwamoto K, Bundo M, Kato T: Altered expression of mitochondria-related genes in postmortem brains of patients with bipolar disorder or schizophrenia, as revealed by large-scale DNA microarray analysis. Hum Mol Genet 2005, 14:241-253.

23. Iwamoto K, Bundo M, Washizuka S, Kakiuchi C, Kato T: Expression of HSPF1 and LIM in the lymphoblastoid cells derived from patients with bipolar disorder and schizophrenia. J Hum Genet 2004, 49:227-231.

24. Choi KH, Zepp ME, Higgs BW, Weickert CS, Webster MJ: Expression profiles of schizophrenia susceptibility genes during human prefrontal cortical development. J Psychiatry Neurosci 2009, 34:450-458.

25. Kim S, Webster MJ: Correlation analysis between genome-wide expression profiles and cytoarchitectural abnormalities in the prefrontal cortex of psychiatric disorders. Mol Psychiatry 2010, 15:326-336.

26. Klempan TA, Ernst C, Deleva V, Labonte B, Turecki G: Characterization of QKI gene expression, genetics, and epigenetics in suicide victims with major depressive disorder. Biol Psychiatry 2009, 66:824-831.

27. Klempan TA, Sequeira A, Canetti L, Lalovic A, Ernst C, ffrench-Mullen J, Turecki G: Altered expression of genes involved in ATP biosynthesis and GABAergic neurotransmission in the ventral prefrontal cortex of suicides with and without major depression. Mol Psychiatry 2009, 14:175-189.

28. Sequeira A, Mamdani F, Ernst C, Vawter MP, Bunney WE, Lebel V, Rehal S, Klempan T, Gratton A, Benkelfat C, et al: Global brain gene expression analysis links glutamatergic and GABAergic alterations to suicide and major depression. PLoS One 2009, 4:e6585.

29. Choi KH, Elashoff M, Higgs BW, Song J, Kim S, Sabunciyan S, Diglisic S, Yolken $\mathrm{RH}$, Knable MB, Torrey EF, Webster MJ: Putative psychosis genes in the prefrontal cortex: combined analysis of gene expression microarrays. BMC Psychiatry 2008, 8:87.

30. Hakak Y, Walker JR, Li C, Wong WH, Davis KL, Buxbaum JD, Haroutunian V, Fienberg AA: Genome-wide expression analysis reveals dysregulation of myelination-related genes in chronic schizophrenia. Proc Natl Acad Sci U S A 2001, 98:4746-4751.

31. Bernard R, Kerman IA, Thompson RC, Jones EG, Bunney WE, Barchas JD, Schatzberg AF, Myers RM, Akil H, Watson SJ: Altered expression of glutamate signaling, growth factor, and glia genes in the locus coeruleus of patients with major depression. Mol Psychiatry 2010.

32. Prabakaran S, Swatton JE, Ryan MM, Huffaker SJ, Huang JT, Griffin JL, Wayland M, Freeman T, Dudbridge F, Lilley KS, et al: Mitochondrial dysfunction in schizophrenia: evidence for compromised brain metabolism and oxidative stress. Mol Psychiatry 2004, 9:684-697, 643.

33. Kim S, Choi KH, Baykiz AF, Gershenfeld HK: Suicide candidate genes associated with bipolar disorder and schizophrenia: an exploratory gene expression profiling analysis of post-mortem prefrontal cortex. BMC Genomics 2007, 8:413.

34. Webster MJ, O'Grady J, Kleinman JE, Weickert CS: Glial fibrillary acidic protein mRNA levels in the cingulate cortex of individuals with depression, bipolar disorder and schizophrenia. Neuroscience 2005, 133:453-461.

35. Hashimoto T, Volk DW, Eggan SM, Mirnics K, Pierri JN, Sun Z, Sampson AR, Lewis DA: Gene expression deficits in a subclass of GABA neurons in the prefrontal cortex of subjects with schizophrenia. J Neurosci 2003, 23:6315-6326.

36. Hsu PC, Yang UC, Shih KH, Liu CM, Liu YL, Hwu HG: A protein interaction based model for schizophrenia study. BMC Bioinformatics 2008, 9(Suppl 12):S23.

37. Lee SA, Chan CH, Chen TC, Yang CY, Huang KC, Tsai CH, Lai JM, Wang FS, Kao $C Y$, Huang CY: POINeT: protein interactome with sub-network analysis and hub prioritization. BMC Bioinformatics 2009, 10:114.

38. Hubbell E, Liu WM, Mei R: Robust estimators for expression analysis. Bioinformatics 2002, 18:1585-1592.

39. Iwamoto K, Kakiuchi C, Bundo M, Ikeda K, Kato T: Molecular characterization of bipolar disorder by comparing gene expression profiles of postmortem brains of major mental disorders. Mol Psychiatry 2004, 9:406-416.

40. Su Al, Wiltshire T, Batalov S, Lapp H, Ching KA, Block D, Zhang J, Soden R, Hayakawa M, Kreiman $G$, et al: A gene atlas of the mouse and human proteinencoding transcriptomes. Proc Natl Acad Sci U S A 2004, 101:6062-6067.

41. Chen TC, Lee SA, Chan CH, Juang YL, Hong YR, Huang YH, Lai JM, Kao CY, Huang CY: Cliques in mitotic spindle network bring kinetochoreassociated complexes to form dependence pathway. Proteomics 2009 9:4048-4062.

42. Spirin V, Mirny LA: Protein complexes and functional modules in molecular networks. P Natl Acad Sci USA 2003, 100:12123-12128.

43. Ruepp A, Waegele B, Lechner M, Brauner B, Dunger-Kaltenbach I, Fobo G, Frishman G, Montrone C, Mewes HW: CORUM: the comprehensive resource of mammalian protein complexes-2009. Nucleic Acids Res 2010, 38:D497-501.

44. Keshava Prasad TS, Goel R, Kandasamy K, Keerthikumar S, Kumar S, Mathivanan S, Telikicherla D, Raju R, Shafreen B, Venugopal A, et al: Human Protein Reference Database-2009 update. Nucleic Acids Res 2009, 37: D767-772.

45. Junker BH, Koschutzki D, Schreiber F: Exploration of biological network centralities with CentiBiN. BMC Bioinformatics 2006, 7:219.

46. Jeong $H$, Mason SP, Barabasi AL, Oltvai ZN: Lethality and centrality in protein networks. Nature 2001, 411:41-42.

47. Hsu DF, Taksa I: Comparing rank and score combination methods for data fusion in information retrieval. Inform Retrieval 2005, 8:449-480.

48. Camon E, Magrane M, Barrell D, Lee V, Dimmer E, Maslen J, Binns D, Harte N, Lopez R, Apweiler R: The Gene Ontology Annotation (GOA) Database: sharing knowledge in Uniprot with Gene Ontology. Nucleic Acids Research 2004, 32:D262-D266.

49. Dennis G Jr., Sherman BT, Hosack DA, Yang J, Gao W, Lane HC, Lempicki RA: DAVID: Database for Annotation, Visualization, and Integrated Discovery. Genome Biol 2003, 4:P3.

50. Medina I, Carbonell J, Pulido L, Madeira SC, Goetz S, Conesa A, Tarraga J, Pascual-Montano A, Nogales-Cadenas R, Santoyo J, et al: Babelomics: an integrative platform for the analysis of transcriptomics, proteomics and genomic data with advanced functional profiling. Nucleic Acids Res 2010, 38:W210-213.

51. Al-Shahrour F, Minguez P, Tarraga J, Medina I, Alloza E, Montaner D, Dopazo J: FatiGO +: a functional profiling tool for genomic data. Integration of functional annotation, regulatory motifs and interaction data with microarray experiments. Nucleic Acids Res 2007, 35:W91-96.

52. Yu W, Clyne M, Khoury MJ, Gwinn M: Phenopedia and Genopedia: disease-centered and gene-centered views of the evolving knowledge of human genetic associations. Bioinformatics 2010, 26:145-146.

53. Hindorff LA, Sethupathy P, Junkins HA, Ramos EM, Mehta JP, Collins FS, Manolio TA: Potential etiologic and functional implications of genomewide association loci for human diseases and traits. Proc Natl Acad Sci U S A 2009, 106:9362-9367.

54. Stenson PD, Ball EV, Howells K, Phillips AD, Mort M, Cooper DN: The Human Gene Mutation Database: providing a comprehensive central mutation database for molecular diagnostics and personalized genomics. Hum Genomics 2009, 4:69-72.

55. Andreasen NC, Nopoulos P, O'Leary DS, Miller DD, Wassink T, Flaum M: Defining the phenotype of schizophrenia: cognitive dysmetria and its neural mechanisms. Biol Psychiatry 1999, 46:908-920. 
56. Koechlin E, Hyafil A: Anterior prefrontal function and the limits of human decision-making. Science 2007, 318:594-598.

57. Glatt SJ, Chandler SD, Bousman CA, Chana G, Lucero GR, Tatro E, May T, Lohr JB, Kremen WS, Everall IP, Tsuang MT: Alternatively spliced genes as biomarkers for schizophrenia, bipolar disorder and psychosis: a bloodbased spliceome-profiling exploratory study. Curr Pharmacogenomics Person Med 2009, 7:164-188.

58. Belsham B: Glutamate and its role in psychiatric illness. Hum Psychopharmacol 2001, 16:139-146.

59. Manji HK, Chen G: PKC, MAP kinases and the bcl-2 family of proteins as long-term targets for mood stabilizers. Mol Psychiatry 2002, 7(Suppl 1): S46-56.

60. Gaspar PA, Bustamante ML, Silva H, Aboitiz F: Molecular mechanisms underlying glutamatergic dysfunction in schizophrenia: therapeutic implications. J Neurochem 2009, 111:891-900.

61. Tsai G, Coyle JT: Glutamatergic mechanisms in schizophrenia. Annu Rev Pharmacol Toxicol 2002, 42:165-179.

62. Verge B, Alonso Y, Valero J, Miralles C, Vilella E, Martorell L: Mitochondrial DNA (mtDNA) and schizophrenia. Eur Psychiatry 2011, 26:45-56.

63. Clay HB, Sillivan S, Konradi C: Mitochondrial dysfunction and pathology in bipolar disorder and schizophrenia. Int J Dev Neurosci 2011, 29:311-324

64. Gentry KM, Nimgaonkar VL: Mitochondrial DNA variants in schizophrenia: association studies. Psychiatr Genet 2000, 10:27-31.

65. Arnsten AF: Prefrontal cortical network connections: key site of vulnerability in stress and schizophrenia. Int J Dev Neurosci 2011, 29:215-223.

66. Anderson G: Neuronal-immune interactions in mediating stress effects in the etiology and course of schizophrenia: role of the amygdala in developmental co-ordination. Med Hypotheses 2011, 76:54-60.

67. Bennett AOM: Stress and anxiety in schizophrenia and depression: glucocorticoids, corticotropin-releasing hormone and synapse regression. Aust N Z J Psychiatry 2008, 42:995-1002.

68. Hahn MW, Kern AD: Comparative genomics of centrality and essentiality in three eukaryotic protein-interaction networks. Mol Biol Evol 2005, 22:803-806.

69. El Kasmi KC, Smith AM, Williams L, Neale G, Panopoulos AD, Watowich SS, Hacker H, Foxwell BM, Murray PJ: Cutting edge: A transcriptional repressor and corepressor induced by the STAT3-regulated anti-inflammatory signaling pathway. J Immunol 2007, 179:7215-7219.

70. Barrenas F, Chavali S, Holme P, Mobini R, Benson M: Network properties of complex human disease genes identified through genome-wide association studies. PLoS One 2009, 4:e8090

71. Yamayoshi S, Noda T, Ebihara H, Goto H, Morikawa Y, Lukashevich IS, Neumann G, Feldmann $H$, Kawaoka Y: Ebola virus matrix protein VP40 uses the COPII transport system for its intracellular transport. Cell Host Microbe 2008, 3:168-177.

72. Wilson MD, Wang D, Wagner R, Breyssens $H$, Gertsenstein $M$, Lobe C, Lu X, Nagy A, Burke RD, Koop BF, Howard PL: ARS2 is a conserved eukaryotic gene essential for early mammalian development. Mol Cell Biol 2008, 28:1503-1514

73. Chavali S, Barrenas F, Kanduri K, Benson M: Network properties of human disease genes with pleiotropic effects. BMC Syst Biol 2010, 4:78.

74. Sebat J, Levy DL, McCarthy SE: Rare structural variants in schizophrenia: one disorder, multiple mutations; one mutation, multiple disorders. Trends Genet 2009, 25:528-535.

75. Purcell SM, Wray NR, Stone JL, Visscher PM, O'Donovan MC, Sullivan PF, Sklar P: Common polygenic variation contributes to risk of schizophrenia and bipolar disorder. Nature 2009, 460:748-752.

76. Ivleva $E$, Thaker G, Tamminga CA: Comparing genes and phenomenology in the major psychoses: schizophrenia and bipolar 1 disorder. Schizophr Bull 2008, 34:734-742.

77. Lichtenstein P, Yip BH, Bjork C, Pawitan Y, Cannon TD, Sullivan PF, Hultman CM: Common genetic determinants of schizophrenia and bipolar disorder in Swedish families: a population-based study. Lancet 2009, 373:234-239

78. Moskvina V, Craddock N, Holmans P, Nikolov I, Pahwa JS, Green E, Owen MJ, O'Donovan MC: Gene-wide analyses of genome-wide association data sets: evidence for multiple common risk alleles for schizophrenia and bipolar disorder and for overlap in genetic risk. Mol Psychiatry 2009, 14:252-260.
79. Owen MJ, Craddock N, Jablensky A: The genetic deconstruction of psychosis. Schizophr Bull 2007, 33:905-911.

80. Ghazanfari N, Fernandez KJ, Murata Y, Morsch M, Ngo ST, Reddel SW, Noakes PG, Phillips WD: Muscle specific kinase: organiser of synaptic membrane domains. Int J Biochem Cell Biol 2011, 43:295-298.

81. Maselli RA, Arredondo J, Cagney O, Ng JJ, Anderson JA, Williams C, Gerke BJ, Soliven B, Wollmann RL: Mutations in MUSK causing congenital myasthenic syndrome impair MuSK-Dok-7 interaction. Hum Mol Genet 2010, 19:2370-2379.

82. Yoritaka A, Shimo Y, Inoue Y, Yoshino H, Hattori N: Nonmotor Symptoms in Patients with PARK2 Mutations. Parkinsons Dis 2011, 2011:473640.

83. Yamamura Y: The long journey to the discovery of PARK2. Neuropathology 2010.

84. Poulogiannis $\mathrm{G}, \mathrm{Mclntyre} \mathrm{RE}$, Dimitriadi $\mathrm{M}$, Apps JR, Wilson $\mathrm{CH}$, Ichimura $\mathrm{K}$, Luo F, Cantley LC, Wyllie AH, Adams DJ, Arends MJ: PARK2 deletions occur frequently in sporadic colorectal cancer and accelerate adenoma development in Apc mutant mice. Proc Natl Acad Sci U S A 2010, 107:15145-15150.

85. Verkerk AJ, Schot R, Dumee B, Schellekens K, Swagemakers S, BertoliAvella AM, Lequin MH, Dudink J, Govaert P, van Zwol AL, et al: Mutation in the AP4M1 gene provides a model for neuroaxonal injury in cerebral palsy. Am J Hum Genet 2009, 85:40-52.

86. Kirby BP, Waddington $\mathrm{LL}$, O'Tuathaigh CM: Advancing a functional genomics for schizophrenia: psychopathological and cognitive phenotypes in mutants with gene disruption. Brain Res Bull 2010, 83:162-176.

87. Shiozawa S, Kawai K, Okada Y, Tomioka I, Maeda T, Kanda A, Shinohara H, Suemizu H, James Okano H, Sotomaru Y, et al: Gene targeting and subsequent site-specific transgenesis at the beta-actin (ACTB) locus in common marmoset embryonic stem cells. Stem Cells Dev 2011.

88. Dahlen A, Mertens F, Mandahl N, Panagopoulos I: Molecular genetic characterization of the genomic ACTB-GLI fusion in pericytoma with $\mathrm{t}$ (7;12). Biochem Biophys Res Commun 2004, 325:1318-1323.

89. Dahlen A, Fletcher CD, Mertens F, Fletcher JA, Perez-Atayde AR, Hicks MJ, Debiec-Rychter M, Sciot R, Wejde J, Wedin R, et al: Activation of the GLI oncogene through fusion with the beta-actin gene (ACTB) in a group of distinctive pericytic neoplasms: pericytoma with $t(7 ; 12)$. Am J Pathol 2004, 164:1645-1653.

90. Silvestre DC, Gil GA, Tomasini N, Bussolino DF, Caputto BL: Growth of peripheral and central nervous system tumors is supported by cytoplasmic c-Fos in humans and mice. PLoS One 2010, 5:e9544.

91. Corral J, Anton Al, Quiroga T, Gonzalez-Conejero R, Pereira J, Roldan V, Vicente $V$, Mezzano D: Influence of the F12 -4 C > T polymorphism on hemostatic tests. Blood Coagul Fibrinolysis 2010, 21:632-639.

92. Kim HJ, Kwon EH, Lee KO, Park IA, Kim SH: Novel deleterious mutation in the F12 gene in a Korean family with severe coagulation factor XII deficiency. Blood Coagul Fibrinolysis 2010, 21:683-686.

93. Gary T, Hafner F, Froehlich H, Stojakovic T, Scharnagl H, Pilger E, Brodmann M: High factor VIII activity, high plasminogen activator inhibitor 1 antigen levels and low factor XII activity contribute to a thrombophilic tendency in elderly venous thromboembolism patients. Acta Haematol 2010, 124:214-217.

94. Messiaen L, Vogt J, Bengesser K, Fu C, Mikhail F, Serra E, Garcia-Linares C, Cooper DN, Lazaro C, Kehrer-Sawatzki H: Mosaic type-1 NF1 microdeletions as a cause of both generalized and segmental neurofibromatosis type-1 (NF1). Hum Mutat 2011, 32:213-219.

95. Harder A, Titze S, Herbst L, Harder T, Guse K, Tinschert S, Kaufmann D,

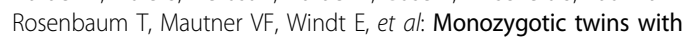
neurofibromatosis type 1 (NF1) display differences in methylation of NF1 gene promoter elements, 5 ' untranslated region, exon and intron 1. Twin Res Hum Genet 2010, 13:582-594.

96. Stenson PD, Mort M, Ball EV, Howells K, Phillips AD, Thomas NS, Cooper DN The Human Gene Mutation Database: 2008 update. Genome Med 2009, 1:13.

97. Erler JT, Linding R: Network-based drugs and biomarkers. J Pathol 2010, 220:290-296

98. Huang PH, Mukasa A, Bonavia R, Flynn RA, Brewer ZE, Cavenee WK, Furnari FB, White FM: Quantitative analysis of EGFRvIll cellular signaling networks reveals a combinatorial therapeutic strategy for glioblastoma. Proc Natl Acad Sci U S A 2007, 104:12867-12872. 
99. Schoeberl B, Pace EA, Fitzgerald JB, Harms BD, Xu L, Nie L, Linggi B, Kalra A, Paragas $V$, Bukhalid $R$, et al: Therapeutically targeting ErbB3: a key node in ligand-induced activation of the ErbB receptor-PI3K axis. Sci Signal 2009, 2:ra31.

100. Aydin D, Filippov MA, Tschape JA, Gretz N, Prinz M, Eils R, Brors B, Muller UC: Comparative transcriptome profiling of amyloid precursor protein family members in the adult cortex. BMC Genomics 2011, 12:160

101. Anliker B, Muller $\mathrm{U}$ : The functions of mammalian amyloid precursor protein and related amyloid precursor-like proteins. Neurodegener Dis 2006, 3:239-246.

102. Devi L, Prabhu BM, Galati DF, Avadhani NG, Anandatheerthavarada HK: Accumulation of amyloid precursor protein in the mitochondrial import channels of human Alzheimer's disease brain is associated with mitochondrial dysfunction. J Neurosci 2006, 26:9057-9068.

doi:10.1186/1471-2105-12-S13-S20

Cite this article as: Lee et al: Construction and analysis of the proteinprotein interaction networks for schizophrenia, bipolar disorder, and major depression. BMC Bioinformatics 2011 12(Suppl 13):S20.

\section{Submit your next manuscript to BioMed Central} and take full advantage of:

- Convenient online submission

- Thorough peer review

- No space constraints or color figure charges

- Immediate publication on acceptance

- Inclusion in PubMed, CAS, Scopus and Google Scholar

- Research which is freely available for redistribution

Submit your manuscript at www.biomedcentral.com/submit
Ciomed Central 